\title{
Is hyperfiltration associated with the future risk of developing diabetic nephropathy? A meta-analysis
}

\author{
G. M. Magee • R. W. Bilous • C. R. Cardwell • \\ S. J. Hunter • F. Kee • D. G. Fogarty
}

Received: 20 November 2008 / Accepted: 21 December 2008 / Published online: 7 February 2009

(C) Springer-Verlag 2009

\begin{abstract}
Aims/hypothesis Glomerular hyperfiltration is a wellestablished phenomenon occurring early in some patients with type 1 diabetes. However, there is no consistent answer regarding whether hyperfiltration predicts later development of nephropathy. We performed a systematic review and meta-analysis of observational studies that compared the risk of developing diabetic nephropathy in patients with and without glomerular hyperfiltration and also explored the impact of baseline GFR.

Methods A systematic review and meta-analysis was carried out. Cohort studies in type 1 diabetic participants were included if they contained data on the development of incipient or overt nephropathy with baseline measurement of GFR and presence or absence of hyperfiltration.

Results We included ten cohort studies following 780 patients. After a study median follow-up of 11.2 years, 130 patients had developed nephropathy. Using a random
\end{abstract}

\author{
G. M. Magee $(\bowtie) \cdot$ S. J. Hunter \\ Regional Centre for Diabetes and Endocrinology, Level 1, \\ Royal Victoria Hospital, \\ Grosvenor Road, \\ Belfast BT12 6BA, UK \\ e-mail: gmagee13@qub.ac.uk \\ R. W. Bilous \\ Newcastle University, \\ Newcastle Upon Tyne, UK \\ R. W. Bilous \\ James Cook University Hospital, \\ Middlesbrough, UK \\ C. R. Cardwell $\cdot$ F. Kee $\cdot$ D. G. Fogarty \\ Department of Epidemiology and Public Health, \\ School of Medicine and Dentistry, Queen's University, \\ Belfast, Northern Ireland, UK
}

effects model, the pooled odds of progression to a minimum of microalbuminuria in patients with hyperfiltration was 2.71 (95\% CI 1.20-6.11) times that of patients with normofiltration. There was moderate heterogeneity (heterogeneity test $p=0.05$, measure of degree of inconsistency= $48 \%$ ) and some evidence of funnel plot asymmetry, possibly due to publication bias. The pooled weighted mean difference in baseline GFR was $13.8 \mathrm{ml} \mathrm{min}^{-1} 1.73 \mathrm{~m}^{-2}$ (95\% CI 5.0-22.7) greater in the group progressing to nephropathy than in those not progressing (heterogeneity test $p<0.01$ ).

Conclusions/interpretation In published studies, individuals with glomerular hyperfiltration were at increased risk of progression to diabetic nephropathy using study level data. Further larger studies are required to explore this relationship and the role of potential confounding variables.

Keywords Diabetic nephropathy · Glomerular hyperfiltration · Meta-analysis · Observational studies . Progression

\section{Abbreviation \\ $I^{2} \quad$ Measure of degree of inconsistency}

\section{Introduction}

Glomerular hyperfiltration is a phenomenon found early in the clinical course of diabetes and its presence has been suggested to be a risk factor for future diabetic nephropathy [1]. In animal studies, when new-onset diabetes is induced by streptozotocin in Munich-Wistar rats, single nephron GFR is increased in animals with moderate hyperglycaemia $[2,3]$. Clinically, GFR is increased in newly diagnosed type 1 diabetic patients compared with non diabetic patients of a 
similar age. Moreover, in approximately $25-40 \%$ of patients with type 1 diabetes, GFR can increase to as much as 160 $180 \mathrm{ml} / \mathrm{min}$. This is assumed to be related to metabolic control, as reduction of blood glucose with insulin therapy returns GFR to near normal levels $[4,5]$.

Glomerular hyperfiltration has been attributed to abnormalities in the glomerulus and glomerular vessels. GFR is determined by renal plasma flow, the transmembrane hydraulic pressure gradients and the ultrafiltration coefficient. Renal plasma flow is reliant on changes between afferent and efferent renal arteriolar resistance; the transmembrane hydraulic pressure gradient is the difference between the mean pressure in the glomerular capillary and the proximal tubule; and the ultrafiltration coefficient is related to the filtration surface area and its permeability. All of these factors are altered in patients with diabetes, although the timing of these dynamic changes is still unclear [6-8].

Uncertainty remains regarding whether glomerular haemodynamic changes similar to those found in patients with type 1 diabetes mellitus are also present in type 2 diabetes. In studies in Pima Indians, GFR was found to be $15 \%$ higher in recent-onset type 2 diabetic patients [9]. However, these changes were no longer significant when corrected for body surface area and were not confirmed by another smaller study [10]. Additionally, in longitudinal studies the GFR was found to be elevated at the onset of type 2 diabetes and remained so until the onset of overt nephropathy [11]. Similar changes have been demonstrated in white patients, with hyperfiltration present in $16 \%$ of 110 previously untreated type 2 diabetic patients [12]. Further cross-sectional studies measuring GFR isotopically have also demonstrated hyperfiltration in various racial groups [13-17].

Renal haemodynamics are likely to play a crucial role in the progression of diabetic nephropathy and may even contribute to its initiation. The available evidence on hyperfiltration risk in human studies is, however, conflicting, while the power of many studies to determine whether hyperfiltration predicts later development of nephropathy is limited. Therefore we performed a systematic review and meta-analysis of studies that compared the risk of developing diabetic nephropathy in type 1 diabetic patients with and without glomerular hyperfiltration at baseline; we also assessed the effect on progression to nephropathy of baseline GFR measurements as a more continuous variable.

\section{Methods}

Literature search MEDLINE and EMBASE were searched from the start date of each source to March 2008 using the search strategy: (Diabetes mellitus, type 1 or Diabetes complications or Diabetes or Diabetes mellitus, type 2 or Diabetes mellitus) and (Nephropathy or Incipient or
Diabetic nephropathies or Overt or Proteinuria or Albuminuria or Microalbuminuria) and (Glomerular filtration rate or Hyperfiltration) and (Cohort studies or Case-control studies). There were no limits on language. Abstracts were screened independently by two investigators (G. M. Magee and D. G. Fogarty) and full text articles were retrieved if relevant. Bibliographies of retrieved papers were also searched.

Inclusion and exclusion criteria Studies with type 1 diabetes were included if they contained data on the development of incipient or overt nephropathy over time. Development of diabetic nephropathy was defined by the progression from normoalbuminuria to microalbuminuria or macroalbuminuria during the duration of follow-up. Albumin excretion rates categorising incipient or overt nephropathy were taken as stated by the individual papers, as they were dependent on the assay used by each laboratory. Data on patients who developed transient or intermittent microalbuminuria, as defined in the studies, were not included in the analysis.

Studies also had to include baseline mean GFR measurements or a baseline determination of the presence or absence of hyperfiltration. The level of hyperfiltration was usually defined by the studies depending upon the method of GFR determination employed. This information enabled us to identify a group of patients who were hyperfiltering at the beginning of the studies and a group with normal GFR, and extract the number of patients in each group who subsequently developed diabetic nephropathy. To enable GFR to be assessed as a continuous measure, the baseline mean $( \pm \mathrm{SD})$ GFR of those who later developed and did not develop nephropathy was also extracted from the papers where possible. All relevant papers were included and attempts were made to contact original authors if data were missing. Any disagreements in numbers were resolved by consensus between G. M. Magee, C. R. Cardwell and D. G. Fogarty. Studies or cases in studies were excluded if they were not normoalbuminuric at baseline or if follow-up data were missing.

Data extraction Eligible studies were assessed independently by two reviewers (G. M. Magee and C. R. Cardwell). Study information on country, year of publication, duration of follow-up, duration of diabetes at baseline, age of diagnosis of diabetes, a measure of glycaemic control and blood pressure was also retrieved. Not all studies defined a level for hyperfiltration. In these cases, a level greater or equal to $140 \mathrm{ml} \mathrm{min}^{-1} 1.73 \mathrm{~m}^{-2}$ was used arbitrarily.

Statistical analysis ORs and their SEs were calculated for the association between progression to incipient or overt nephropathy and the baseline presence of hyperfiltration for 
each study. A combined pooled OR was then derived using a random effects model, as we had anticipated some between-study heterogeneity, given that observational studies were being reviewed. Mean baseline differences in GFR between patients progressing to nephropathy and those without nephropathy during follow-up were also calculated, enabling a pooled weighted mean difference in GFR to be formulated, again using a random effects model to allow for between-study heterogeneity. Tests for heterogeneity between studies were conducted and the measure of degree of inconsistency $\left(I^{2}\right)$ statistic was used to quantify the degree of this heterogeneity [18]. This value describes the total variation across the studies that is due to heterogeneity rather than chance (with $I^{2}$ values of $25 \%, 50 \%$ and $75 \%$ being tentatively considered low, moderate and high heterogeneity respectively).

Publication bias was analysed by examining a funnel plot looking for asymmetry in plotted ORs against the SE of the logarithm of the ORs (a measure of study size). Begg's and Egger's tests for publication bias were also applied [19, 20]. All statistical analyses were performed using Stata 9.0 software (Stata, College Station, TX, USA).

\section{Results}

A total of 23 papers was retrieved for further evaluation, from which three cohort studies were selected for the metaanalysis. A further eight studies with the desired information were retrieved from studying bibliographies. We excluded 77 abstracts, five due to the presence of baseline microalbuminuria or proteinuria, 14 due to study design, four because studies contained participants without diabetes and 15 because other causes of nephropathy were included. Ten excluded studies described the use of novel markers and 29 others were excluded as they did not have any patients with GFR in the hyperfiltration range at baseline or because data were presented in such a way that the baseline GFRs could not be derived. One initially included report was subsequently removed from the analysis because it comprised patients with type 2 diabetes only, and as such was felt to be not comparable to the other studies [21]. In the end, ten cohort studies from six countries following 780 patients were included in this meta-analysis [22-31]. The publication years spanned three decades from 1984 to 2006 and all studies were of type 1 diabetic patients. The mean age at diabetes diagnosis was 12.3 years. The definition of hyperfiltration across the studies ranged from $\geq 125$ to $\geq 140 \mathrm{ml} \mathrm{min}^{-1} 1.73 \mathrm{~m}^{-2}$. Four studies did not define a level of hyperfiltration and in these, this was arbitrarily taken as $\geq 140 \mathrm{ml} \mathrm{min}^{-1} 1.73 \mathrm{~m}^{-2}$ (Table 1).

At the start of the studies, the mean duration of diabetes was 8.1 years and the mean overall follow-up of the cohorts was 11.2 years (Table 1). No studies had any participants on anti-hypertensive medication at baseline. In the three oldest studies $\mathrm{HbA}_{1 \mathrm{c}}$ was not available as a measure of glycaemic control, two other studies used $\mathrm{HbA}_{1}$ measurements (Table 1). An estimate of $\mathrm{HbA}_{1 \mathrm{c}}(\%)$ was established for these older studies using mean plasma glucose results and the reverse of the formula for estimated average glucose [32]: estimated average glucose $(\mathrm{mmol} / 1)=$ $1.583 \times \mathrm{HbA}_{1 \mathrm{c}}-2.52$ (Table 1). The mean $\mathrm{HbA}_{1 \mathrm{c}}$ of

Table 1 Characteristics of ten studies included in the meta-analysis

\begin{tabular}{|c|c|c|c|c|c|c|c|c|c|c|c|}
\hline \multirow[t]{2}{*}{$\begin{array}{l}\text { First author } \\
\text { [reference no.] }\end{array}$} & \multirow[t]{2}{*}{ Year } & \multirow[t]{2}{*}{ Country } & \multirow{2}{*}{$\begin{array}{l}\text { Hyperfiltration } \\
\text { definition } \\
\left(\mathrm{ml} \mathrm{min} \mathrm{min}^{-1}\right. \\
\left.1.73 \mathrm{~m}^{-2}\right)^{\mathrm{a}}\end{array}$} & \multirow{2}{*}{$\begin{array}{l}\text { Patients } \\
\text { included } \\
(n)\end{array}$} & \multirow{2}{*}{$\begin{array}{l}\text { Mean age at } \\
\text { diagnosis } \\
\text { (years) }\end{array}$} & \multirow{2}{*}{$\begin{array}{l}\text { Mean } \\
\text { follow-up } \\
\text { (years) }\end{array}$} & \multirow{2}{*}{$\begin{array}{l}\text { Mean baseline } \\
\text { diabetes } \\
\text { duration (years) }\end{array}$} & \multicolumn{2}{|c|}{$\begin{array}{l}\text { Mean baseline } \mathrm{HbA}_{1 \mathrm{c}} \\
(\%)\end{array}$} & \multicolumn{2}{|c|}{$\begin{array}{l}\text { Mean baseline blood } \\
\text { pressure }(\mathrm{mmHg})\end{array}$} \\
\hline & & & & & & & & Progression & $\begin{array}{l}\text { No } \\
\text { progression }\end{array}$ & Progression & $\begin{array}{l}\text { No } \\
\text { progression }\end{array}$ \\
\hline Mogensen [22] & 1984 & Denmark & ND & 24 & 12.3 & 10.4 & 12.6 & $6.9^{\mathrm{b}}$ & $7.4^{\mathrm{b}}$ & $135 / 89$ & $124 / 80$ \\
\hline Lervang [23] & 1988 & Denmark & ND & 29 & 18.9 & 18.5 & 3.4 & $9.3^{\mathrm{b}}$ & $7.2^{\mathrm{b}}$ & $118 / 76$ & $119 / 76$ \\
\hline Lervang [24] & 1992 & Denmark & ND & 34 & 7.0 & 12.0 & 7.0 & $10.8^{\mathrm{b}}$ & 9.0 & $128 / 83$ & $115 / 70$ \\
\hline Chiarelli [25] & 1995 & Italy & $140^{\mathrm{c}}$ & 46 & 6.2 & 10.0 & 9.7 & $12.2^{\mathrm{d}}$ & $9.5^{\mathrm{d}}$ & NA & NA \\
\hline Yip [26] & 1996 & England & 135 & 45 & 21.5 & 9.5 & 8.0 & NA & NA & NA & NA \\
\hline Caramori [27] & 1999 & Brazil & $134^{\mathrm{c}}$ & 33 & 25.3 & 8.4 & 6.5 & $11.4^{\mathrm{d}}$ & $9.9^{\mathrm{d}}$ & NA & NA \\
\hline Dahlquist [28] & 2001 & Sweden & 125 & 43 & 6.0 & 18.0 & 10.9 & 12.2 & 12.0 & $121 / 74$ & $115 / 74$ \\
\hline Amin [29] & 2005 & England & 125 & 273 & 9.3 & 10.9 & 5.1 & 10.8 & 9.7 & NA & NA \\
\hline Steinke [30] & 2005 & USA & 130 & 107 & 8.7 & 5.0 & 8.0 & 9.2 & 8.4 & $114 / 64$ & $114 / 64$ \\
\hline Zerbini [31] & 2006 & Italy & ND & 146 & 7.3 & 9.5 & 9.5 & 9.8 & 9.0 & $119 / 74$ & $118 / 74$ \\
\hline Total & & & & 780 & & & & & & & \\
\hline Mean & & & & & 12. 3 & 11.2 & 8.1 & 10.5 & 9.6 & $123 / 77$ & $118 / 73$ \\
\hline
\end{tabular}

${ }^{a}$ Where not defined (ND), arbitrarily set at $>140 \mathrm{ml} \mathrm{min}^{-1} 1.73 \mathrm{~m}^{-2}$

${ }^{\mathrm{b}} \mathrm{HbA}_{1 \mathrm{c}}$ estimated using reverse estimated average glucose formula (these values omitted when calculating mean)

${ }^{c}$ Single compartment GFR estimation technique

${ }^{\mathrm{d}} \mathrm{HbA}_{1}$ measurements (these values omitted when calculating mean)

NA, not available 


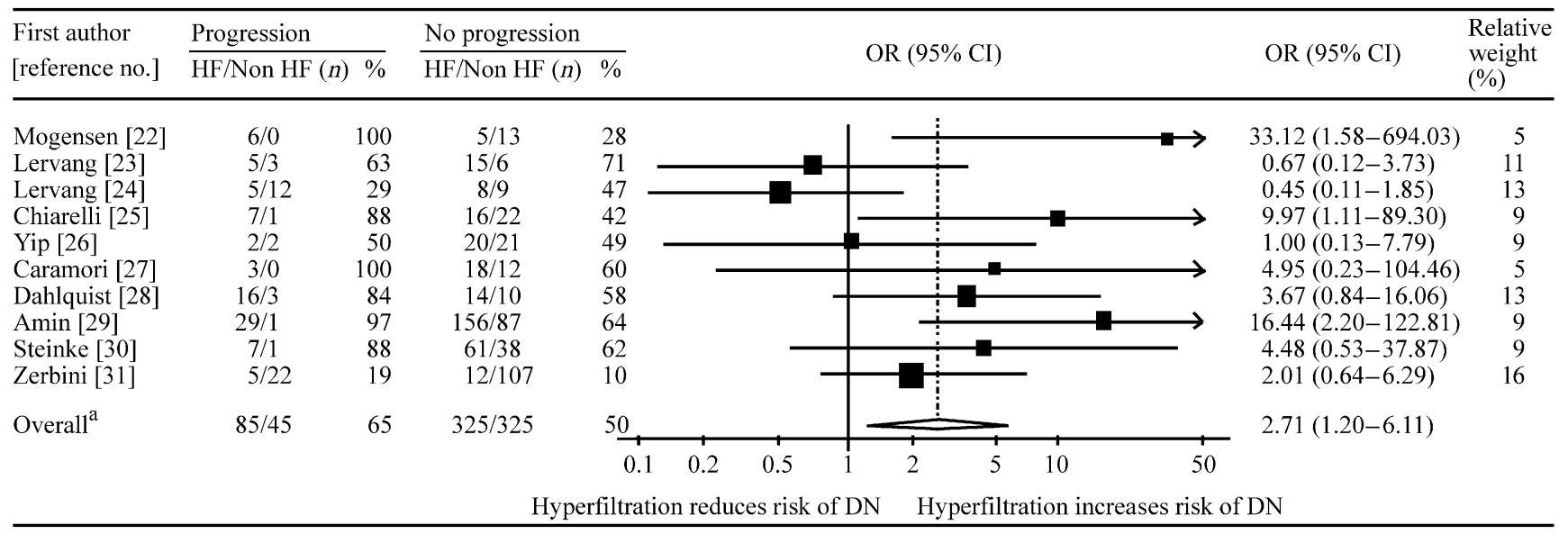

Fig. 1 Forest plot of studies investigating the association between hyperfiltration and progression Number of studies, $n=10$. ${ }^{\mathrm{a}}$ Test for heterogeneity $\chi^{2}=17.15, d f=9.0, p=0.05 ; I^{2}=48(95 \%$ CI $0-75) \%$; test

patients with progression to nephropathy was $10.5 \%$ compared with $9.6 \%$ in those not progressing.

The association between hyperfiltration and progression to diabetic nephropathy is shown in Fig. 1. Using the random effects model, the pooled odds of progression to a minimum of incipient nephropathy was 2.71 (95\% CI 1.20 6.11) times those in patients with normofiltration at baseline, but there was evidence of heterogeneity $\left(p=0.05, I^{2}=\right.$ $48 \%$ ). In addition, the funnel plot shown in Fig. 2 suggests some evidence of asymmetry, although formal tests were not significant (Begg's $p=0.2$, Egger's $p=0.1$ ).

Of the ten studies included, nine compared the mean difference in GFR in the groups with and without progression. One study could not be included for analysis on this point, as the relevant data could not be extracted [26]. In the nine studies included, the combined mean baseline GFR was $13.8 \mathrm{ml} \mathrm{min}^{-1} 1.73 \mathrm{~m}^{-2}$ greater in the patient groups progressing to nephropathy than in those not progressing. However, there was marked heterogeneity $\left(I^{2}=77 \%[95 \%\right.$ CI 57-88\%]) between studies, indicating that it may not be appropriate to produce overall estimates (Fig. 3). The funnel

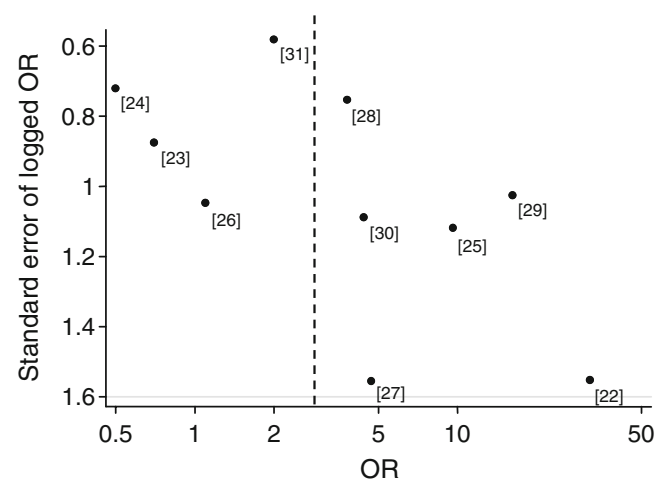

Fig. 2 Funnel plot of the association between hyperfiltration and diabetic nephropathy. Dashed line, pooled estimate; dots, study as denoted by reference number for overall effect $Z=2.39, p=0.02$. DN, diabetic nephropathy; HF, baseline hyperfiltration

plot (not shown) suggested very little evidence of publication bias (Begg's test $p=0.92$, Egger's test $p=0.99$ ). Analysis excluding the two studies that used an uncorrected single compartment model for GFR calculation did not considerably alter the overall OR or improve heterogeneity.

\section{Discussion}

This meta-analysis indicates that type 1 diabetic patients with hyperfiltration are 2.7 times more likely to progress to incipient nephropathy than those with normofiltration and that patients who progressed had a higher baseline GFR.

The strength of this analysis is that it is the first study combining estimates from previous smaller observational studies on the risk of progression in the presence of hyperfiltration and thereby allowing more power to detect any differences as significant. However, these findings should be interpreted cautiously, as for both analyses there was apparent heterogeneity. Furthermore, in the hyperfiltration analysis, although not detected in formal tests, a funnel plot supplied evidence of asymmetry, with small published studies observing more marked increases in the risk of progression to nephropathy after hyperfiltration. This pattern is consistent with publication bias (resulting from small studies observing no associations or inverse associations not being published), which, if present, would result in the combined OR overestimating the increased risk of progression to nephropathy after hyperfiltration.

The association between progression and hyperfiltration had an $I^{2}$ value of $48 \%$, indicating low to moderate heterogeneity, but this was greater $\left(I^{2}=77 \%\right)$ when the mean GFR between patients who progressed and those who did not was compared. There are various explanations for this marked heterogeneity, including differences in the year 


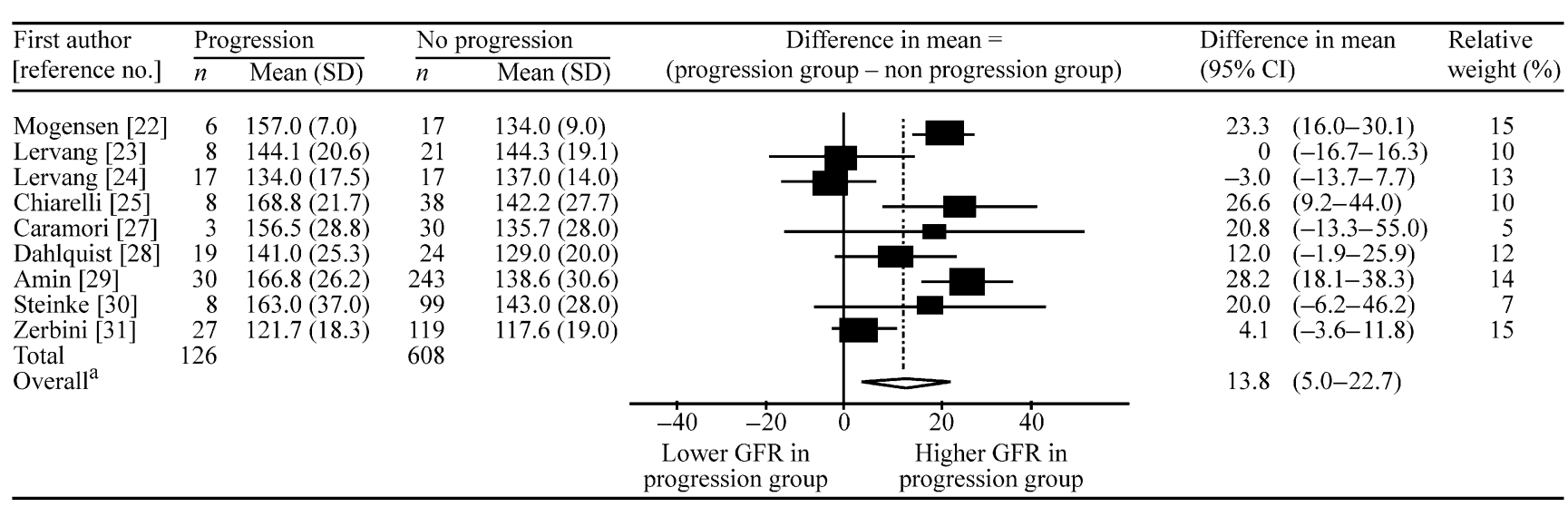

Fig. 3 Forest plot of studies investigating the association between baseline GFR and progression. Number of studies, $n=9$. ${ }^{\mathrm{a}}$ Test for heterogeneity $\chi^{2}=35.24, d f=8, p<0.001 ; I^{2}=77(95 \%$ CI $57-88) \%$; test for overall effect $Z=3.06, p=0.002$

of study, glycaemic control, treatments and improvement in screening for complications.

Various techniques were employed throughout the studies to measure the GFR, with some of the studies using a single compartment analysis. This has been shown to overestimate GFR by as much as $25 \%$ to $30 \%$ in the upper range of clearance values when compared with a two compartment model [33]. The use of this model, if not corrected, would tend to overestimate the numbers of patients with hyperfiltration. When the studies not correcting for this potential weakness were removed from our analysis, heterogeneity did not improve and the combined OR did not markedly change, falling to 2.32 (Fig. 3).

Hyperfiltration has been found to be more prevalent in those with recent onset of diabetes and when glycaemic control is poor $[1,4,5]$. It would therefore be essential to compare duration of diabetes at entry into the study, as patients with shorter disease duration are more likely to have hyperfiltration. The mean duration of diabetes at entry into the studies analysed was 8.1 years, but this ranged from 3.4 to 12.6 years $[22,23]$. Patients should therefore have been on established glycaemic therapy even in the studies with the shortest disease duration at baseline. Two studies had calculated odds strongly against hyperfiltration as a risk factor for progression [23, 24]. The first of these had the shortest duration of diabetes, but participants were diagnosed at an older mean age of 18.9 years and followed up for the longest period of time (18.5 years). It is therefore surprising that this group, with a $69 \%$ prevalence of hyperfiltration, had the lowest risk of progressing to nephropathy. It is generally recognised that younger age of diabetes onset also leads to a younger age of progression [34]; however, these older patients were diagnosed years after exposure to pubertal hormonal changes, which are thought to increase hyperfiltration, and perhaps this plays some part in confounding against their overall risk of progression [29]. In other words, the pathophysiology of increased GFR may differ at different ages and these differences may themselves confer variable nephropathy risk.

In one study, the calculated odds of progression at 33.1 was double that of the next nearest $(16.4)$ [22, 29]. There are a number of possible explanations for this disparity of effect, including the fact that this study was the first of its kind, and also the smallest. In addition, progression to microalbuminuria was defined as an increase in urinary albumin excretion (determined by radioimmunoassay) by a factor of more than 3 at follow-up. When compared with all other studies, where microalbuminuria was generally defined as 20 to $200 \mu \mathrm{g} /$ min, this approach may lead to overestimation of progression to microalbuminuria based upon lower initial urinary albumin excretion. Also, in this study, patients who progressed had a markedly higher baseline GFR (all $>150 \mathrm{ml} \mathrm{min}^{-1} 1.73 \mathrm{~m}^{-2}$ ) than those not progressing compared with some of the later studies. The role of different levels of hyperfiltration could only be assessed in a larger study or with individual patient level data.

It has been proposed that high glomerular plasma flow increases intracapillary pressure; there is a relative constriction of the efferent glomerular arteriole resulting in a flux of plasma proteins into the mesangium $[2,35,36]$. This, in turn, leads to proliferation of mesangial cells and matrix, a forerunner of glomerulosclerosis. One potential cellular mechanism whereby these haemodynamic changes may lead to this sclerotic process is the effect of stretch induced by increased intraglomerular pressure on increasing fibronectin levels in mesangial cells via p38 mitogenactivated protein kinase, as has been demonstrated in mouse models [37]. This has been shown to increase podocyte hypertrophy in vitro and leads to local activation of the angiotensin system $[38,39]$.

Hyperglycaemia can cause an increase in GFR, so the role of glycaemic control and diabetes treatment is important. Comparison of baseline glycaemic control across the studies showed that the mean $\mathrm{HbA}_{1 \mathrm{c}}$ in patients with 
progression was $10.5 \%$ vs $9.6 \%$ in those not progressing. This may be a confounder in the overall calculated odds of progression. Reported baseline blood pressure was also higher, when available, in the progressing patients $(123 / 77$ vs $118 / 73 \mathrm{mmHg}$ ). An adjusted OR would be required to correct for the potential confounding factors of glycaemic control, blood pressure and diabetes duration, but in order to achieve this, individual patient level data would be necessary. However, in view of the age of some of the studies involved, the original data are unlikely to be available.

The progression to overt nephropathy as an endpoint was also assessed. However, three of the studies were not specifically designed or of long enough duration to look for proteinuria [29-31] and a further study did not discriminate between incipient and overt nephropathy [24], leaving very small numbers for analysis.

Hyperfiltration has been associated with a greater rate of decline in GFR [40]. Additionally, there is a normal physiological decline in GFR associated with ageing. Most of the individual studies assessed here were not adjusted for age-related decline as a factor in GFR prediction or for the effects of hyperfiltration on promoting a more rapid decline in GFR rather than nephropathy as such, so we were unable to analyse these effects in the identified studies [41-43].

In conclusion, in the identified studies, individuals with type 1 diabetes who had glomerular hyperfiltration or elevated GFR subsequently had an increased risk of developing diabetic nephropathy. However, additional studies using patient level data are required to examine whether this increased risk would persist after adjustment for the confounding effects of glycaemic control, diabetes duration and blood pressure. Confirmation of hyperfiltration as a risk marker might enable future studies to assess how early GFR reduction using agents that block the renin-angiotensinaldosterone system impacts on the development of incipient nephropathy. Ongoing studies are evaluating these drugs, but they are not stratifying treatment based upon baseline GFR $[44,45]$.

Acknowledgements This study was supported by the Northern Ireland Kidney Research Fund and the Metabolic Unit Research Fund.

Duality of interest The authors declare that there is no duality of interest associated with this manuscript.

\section{References}

1. Mogensen CE, Christensen CK, Pedersen MM et al (1990) Renal and glycemic determinants of glomerular hyperfiltration in normoalbuminuric diabetics. J Diabetes Complications 4:159-165
2. Hostetter TH, Troy JL, Brenner BM (1981) Glomerular haemodynamics in experimental diabetes mellitus. Kidney Int 19:410 415

3. Reubi FC (1953) Glomerular filtration rate, renal blood flow and blood viscosity during and after diabetic coma. Circ Res 1:410 413

4. Mogensen CE (1971) Glomerular filtration rate and renal plasma flow in short-term and long-term juvenile diabetes mellitus. Scand J Clin Lab Invest 28:91-100

5. Wiseman MJ, Viberti GC, Keen H (1984) Threshold effect of plasma glucose in the glomerular hyperfiltration of diabetes. Nephron 38:257-260

6. Steffes M, Bilous R, Sutherland D, Mauer S (1992) Cell and matrix components of the glomerular mesangium in type I diabetes. Diabetes 41:679-684

7. Osterby R, Parving H, Hommel E, Jorgensen H, Lokkegaard H (1990) Glomerular structure and function in diabetic nephropathy. Early to advanced stage. Diabetes 39:1057-1063

8. Bak M, Thomsen K, Christiansen T, Flyvbjerg A (2000) Renal enlargement precedes renal hyperfiltration in early experimental diabetes in rats. J Am Soc Nephrol 11:1287-1292

9. Myers BD, Nelson RG, Williams GW et al (1991) Glomerular function in Pima Indians with non insulin-dependent diabetes mellitus of recent onset. J Clin Invest 88:524-530

10. Schmitz A, Christensen T, Jensent FT (1989) Glomerular filtration rate and kidney volume in normoalbuminuric non-insulin-dependent diabetics-lack of glomerular hyperfiltration and renal hypertrophy in uncomplicated NIDDM. Scand J Clin Lab Invest 49:103-108

11. Nelson RG, Bennett PH, Beck GJ et al (1996) Development and progression of renal disease in Pima Indians with non insulin dependent diabetes mellitus. N Engl J Med 335:1636-1642

12. Vora JP, Dolben J, Dean JD et al (1992) Renal haemodynamics in newly presenting non insulin dependent diabetes mellitus. Kidney Int 41:829-835

13. Taniwaki H, Ishimura E, Emoto M et al (2000) Relationship between urinary albumin excretion and glomerular filtration rate in normotensive, non proteinuric patients with type 2 diabetes mellitus. Nephron 86:36-43

14. Palmisano JJ, Lebovitz HE (1989) Renal function in black Americans with type II diabetes. J Diabetes Complications 3:40-44

15. Bruce R, Rutland M, Cundy T (1994) Glomerular hyperfiltration in young Polynesians with type 2 diabetes. Diabetes Res Clin Pract 25:155-160

16. Lee KU, Park JY, Hwang IR et al (1995) Glomerular hyperfiltration in Koreans with non-insulin-dependent diabetes mellitus. Am J Kidney Dis 26:722-726

17. Vedel P, Obel J, Nielsen FS et al (1996) Glomerular hyperfiltration in microalbuminuric NIDDM patients. Diabetologia 39:1584-1589

18. Higgins JPT, Thompson SG, Deeks JJ, Altman DG (2003) Measuring inconsistency in meta-analyses. BMJ 327:557-560

19. Begg CB, Mazumdar M (1994) Operating characteristics of a rank correlation test for publication bias. Biometrics 50:1088-1101

20. Egger M, Davey Smith G, Schneider M, Minder C (1997) Bias in meta-analysis detected by a simple graphical test. BMJ 315:629-634

21. Murussi M, Gross JL, Silveiro SP (2006) Glomerular filtration rate changes in normoalbuminuric and microalbuminuric Type 2 diabetic patients and normal individuals: A 10-year follow-up. J Diabetes Complications 20:210-215

22. Mogensen CE (1986) Early glomerular hyperfiltration in insulindependent diabetics and late nephropathy. Scand J Clin Lab Invest 46:201-206

23. Lervang HH, Jensen S, Brochner-Mortensen J, Ditzel J (1988) Early glomerular hyperfiltration and the development of late nephropathy in type 1 (insulin-dependent) diabetes mellitus. Diabetologia 31:723-729 
24. Lervang HH, Jensen S, Brochner-Mortensen J, Ditzel J (1992) Does increased glomerular filtration rate or disturbed tubular function early in the course of childhood type 1 diabetes predict the development of nephropathy? Diabet Med 9:635-640

25. Chiarelli F, Verrotti A, Morgese G (1995) Glomerular hyperfiltration increases the risk of developing microalbuminuria in diabetic children. Pediatr Nephrol 9:154-158

26. Yip JW, Jones SL, Wiseman MJ, Hill C, Viberti G (1996) Glomerular hyperfiltration in the prediction of nephropathy in IDDM: a 10-year follow-up study. Diabetes 45:1729-1733

27. Caramori M, Gross J, Pecis M, de Azevedo M (1999) Glomerular filtration rate, urinary albumin excretion rate, and blood pressure changes in normoalbuminuric normotensive type 1 diabetic patients: an 8-year follow-up study. Diabetes Care 22:1512-1516

28. Dahlquist G, Stattin E, Rudberg S (2001) Urinary albumin excretion rate and glomerular filtration rate in the prediction of diabetic nephropathy; a long-term follow-up study of childhood onset type-1 diabetic patients. Nephrol Dial Transplant 16:1382-1386

29. Amin R, Turner C, van Aken S et al (2005) The relationship between microalbuminuria and glomerular filtration rate in young type 1 diabetic subjects: The Oxford Regional Prospective Study. Kidney Int 68:1740-1749

30. Steinke JM, Sinaiko AR, Kramer MS et al (2005) The early natural history of nephropathy in type 1 diabetes: predictors of 5 year urinary albumin excretion rate patterns in initially normoalbuminuric patients. Diabetes 54:2164-2171

31. Zerbini G, Bonfanti R, Meschi F et al (2006) Persistent renal hypertrophy and faster decline of glomerular filtration rate precede the development of microalbuminuria in type 1 diabetes. Diabetes 55:2620-2625

32. Manley SE (2008) Estimated average glucose derived from HbAlc (eAG): Report from the European Association for the Study of Diabetes (EASD), Amsterdam 2007. Diabet Med 25:126-128

33. Brøchner-Mortensen J, Rohbrandt K, Lauritzen RB (1977) Precision of single injection $\left[{ }^{51} \mathrm{Cr}\right]$ EDTA plasma clearance and endogenous creatinine clearance determinations in children. Scand J Clin Lab Invest 37:625-629

34. Amin R, Widmer B, Prevost AT et al (2008) Risk of microalbuminuria and progression to macroalbuminuria in a cohort with childhood onset type 1 diabetes: prospective observational study. BMJ 336:697-701

35. O'Bryan GT, Hostetter TH (1997) The renal haemodynamic basis of diabetic nephropathy. Semin Nephrol 17:93-100

36. Olson JL, Hostetter TH, Rennke HG, Brenner BM, Venkatachalam MA (1982) Altered glomerular permselectivity and progressive sclerosis following extreme ablation of renal mass. Kidney Int 22:112-126

37. Gruden G, Zonca S, Hayward A et al (2000) Mechanical stretchinduced fibronectin and transforming growth factor-betal production in human mesangial cells is p38 mitogen-activated protein kinase-dependent. Diabetes 49:655-661

38. Petermann AT, Pippin J, Durvasula R et al (2005) Mechanical stretch induces podocyte hypertrophy in vitro. Kidney Int 67:157166

39. Durvasula RV, Petermann AT, Hiromura K et al (2004) Activation of a local tissue angiotensin system in podocytes by mechanical strain. Kidney Int 65:30-39

40. Perkins BA, Ficociello LH, Ostrander BE et al (2007) Microalbuminuria and the risk for early progressive renal function decline in type 1 diabetes. J Am Soc Nephrol 18:1353-1361

41. Silveiro S, Friedman R, de Azevedo M, Canani L, Gross J (1996) Five-year prospective study of glomerular filtration rate and albumin excretion rate in normofiltering and hyperfiltering normoalbuminuric NIDDM patients. Diabetes Care 19:171-174

42. Premaratne E, Macisaac RJ, Tsalamandris C, Panagiotopoulos S, Smith T, Jerums G (2005) Renal hyperfiltration in type 2 diabetes: effect of age-related decline in glomerular filtration rate. Diabetologia 48:2486-2493

43. Rius F, Pizarro E, Salinas I, Lucas A, Sanmarti A, Romero R (1995) Age as a determinant of glomerular filtration rate in noninsulin-dependent diabetes mellitus. Nephrol Dial Transplant 10:1644-1647

44. Klein R, Zinman B, Gardiner R et al (2005) The relationship of diabetic retinopathy to preclinical diabetic glomerulopathy lesions in type 1 diabetic patients: The Renin-Angiotensin System Study. Diabetes 54:527-533

45. The DIRECT Programme Study Group (2005) The DIabetic REtinopathy Candesartan Trials (DIRECT) programme: baseline characteristics. J Renin Angiotensin Aldosterone Syst 6:25-32 